\title{
Fatores de risco do tecnoestresse em trabalhadores que utilizam tecnologias de informação e comunicação
}

\author{
Mary Sandra Carlotto \\ Universidade Luterana do Brasil
}

\begin{abstract}
Resumo
O estudo objetivou identificar fatores de risco sociodemográficos, laborais e psicossociais em 668 trabalhadores de organizações de Porto Alegre (RS) e região metropolitana. Para a coleta de dados foi utilizada a Escala de Tecnoestresse (RED/TIC) e um questionário para levantamento das demais variáveis. O resultado obtido com relação à dimensão de "Descrença" estabeleceu um perfil de risco constituído por mulheres, com filhos e escolaridade em nível de ensino médio. A dimensão de "Fadiga" constituiu-se por mulheres, sem companheiro, com mais horas de utilização de e-mail, internet e intranet. No tocante a "Ansiedade", identificou-se um perfil de mulheres, com filhos, com ensino médio e que utilizam celular. Mulheres, com idade mais elevada, com companheiro, filhos e que utilizam celular e maior número de horas com TIC fora do horário de trabalho formaram o perfil da "Ineficácia". Não optar por trabalhar com TIC, insatisfação e não realização com o trabalho associaram-se às quatro dimensões do tecnoestresse.
\end{abstract}

Palavras-chave: tecnoestresse; tecnologia de comunicação e informação; TIC; trabalhadores.

\begin{abstract}
Risk factors of technostress in workers on information and communication technologies. The aim of this study was to verify the sociodemographic, work and psychosocial risk factors in 668 subjects from organizations located in Porto Alegre (RS) and metropolitan area. For data collection, the instruments used were the Technostress Scale (RED/ICT) and a questionnaire to survey other variables. In the dimension of Disbelief, we identified a profile constituted of women, with children and high school degree, use of ICT outside working time, use e-mail. In the dimension of Fatigue, women, without partners, were spending more hours using e-mail, internet and intranet. Women, with children and high school degree, using cell phones characterized the profile of Anxiety dimension. To Ineffectiveness, women, older age, with partner and children, who use cell phones and spend more time with ICT out of working hours. Not choosing to work with ICT, dissatisfaction and not feeling fulfilled by the job were associated with the fours dimensions of technostress.
\end{abstract}

Keywords: technostress; information and communication technologies; ICT; workers.

$\mathrm{O}$ atual contexto no qual se insere a sociedade da informação é construído com base nas Tecnologias da Comunicação e Informação (TIC), representando uma profunda mudança na organização da sociedade e da economia. No Brasil, a área tecnológica é responsável por $80 \%$ dos postos de trabalho e, apenas $60 \%$ da força de trabalho se encaixa nesta realidade, recaindo sobre o trabalhador a obrigação de uma especialização e atualização de conhecimento (Ferreira, 2006).

No paradigma tecnoeconômico, centrado no computador, no software, na microeletrônica, na internet e na telefonia móvel, o trabalhador utiliza cada vez mais estas novas ferramentas para conseguir acompanhar e interagir com os diversos estágios de concepção e elaboração de produtos e serviços (Souto, 2006; Valle, 1996). Novas formas de trabalho e organizações se estruturam em torno das TIC, como o teletrabalho, as equipes virtuais e o e-comércio. Tais tecnologias têm incorporado ao seu dia-a-dia pelo menos alguns elementos da interação virtual, envolvendo comunicação não presencial intermediada por e-mail, telefone, videoconferência, etc., sendo crescente o número de equipes compostas por pessoas que se comunicam quase que exclusivamente por meios eletrônicos (Bejarano, Pilatti, Scandelari, \& Oliveira, 2006).

Estas inovações e mudanças tecnológicas se, por um lado, trazem benefícios econômicos para a organização e para muitos aspectos relacionados ao conteúdo do cargo do trabalhador, por outro, podem produzir problemas humanos e sociais os quais têm sido objeto de profundo debate devido às consequências para a saúde mental do trabalhador, já que a introdução de TIC no contexto de trabalho tem proporcionado tanto efeitos positivos tanto quanto negativos para a qualidade de vida do trabalhador 
(Korunka, 2002; Pocinho \& Garcia, 2008).

$\mathrm{O}$ trabalho com TIC requer maior exigência cognitiva e, por conseguinte, maior é a sobrecarga em seus processos mentais. Essa sobrecarga, causada pelos estímulos internos (necessidades e perspectivas pessoais) e externos (exigências dos sistemas produtivos e pressão social), é cada vez maior e recorrente. Diante das características da nova lógica de trabalho, é de se esperar que o estresse seja um fenômeno comum entre os trabalhadores, o que pode ser constatado pelos casos de desequilíbrios psicossomáticos e doenças ocupacionais evidentes e/ou emergentes (Ferrreira, 2006; Pacheco, Ferreira Jr., Pereira, \& Pereira Filho, 2005).

De acordo com Michael (1998), com a inserção da tecnologia no ambiente de trabalho mais pessoas estão propensas ao estresse tecnológico, denominado de tecnoestresse. Sua conceituação está diretamente relacionada aos efeitos psicossociais negativos do uso de TIC. Tecnoestresse, segundo Salanova (2003, 2005), é um estado psicológico negativo relacionado com o uso de TIC, estando condicionado pela percepção de um desajuste entre as demandas e os recursos relacionados ao uso de TIC que conduz a um alto nível de ativação psicofisiológica não prazerosa, levando, assim, ao desenvolvimento de atitudes negativas frente às TIC. É uma doença moderna causada pela inabilidade de lidar com novas tecnologias relacionadas ao uso de computador de forma saudável (Aida, Azlina, \& Balqis, 2007).

Na ótica de Salanova (2005), os principais fatores de risco do tecnoestresse são as altas demandas laborais com uso de TIC e a falta de recursos tecnológicos e sociais para lidar com elas. Com relação às suas consequências, é possível destacar, no âmbito individual, sintomas psicossomáticos, tais como problemas de sono, dores de cabeça, dores musculares, transtornos gastrointestinais, entre outros; e, no âmbito organizacional, o absenteísmo e o baixo desempenho (Salanova, Cifre, \& Martín, 1999). Há de se destacar, quanto a este aspecto, um maior fracasso na resolução dos problemas organizacionais resultantes do alto nível de absenteísmo e rotatividade de seus trabalhadores (Harper, 2000).

Com base no modelo teórico proposto por Salanova, Llorens, Cifre e Nogareda (2007), constituído de três dimensões: 1) Afetiva (ansiedade versus fatiga); 2) Atitudinal (atitude de descrença frente a tecnologias); e 3) Cognitiva (crenças de ineficácia no uso de tecnologias), este estudo observacional analítico transversal (Grimes \& Shulz, 2002) procurou identificar fatores de risco sociodemográficos, laborais e psicossociais do tecnoestresse em trabalhadores que utilizam TIC, em organizações situadas na Região Metropolitana de Porto Alegre, no período de setembro de 2007 a setembro de 2008 .

\section{Método}

\section{Participantes}

Participaram da investigação 668 trabalhadores de organizações localizadas em Porto Alegre (RS) e região metropolitana. Os trabalhadores que constituíram a amostra eram, em sua maioria, mulheres $(59,6 \%)$, solteiros $(57,8 \%)$, sem filhos $(61,4 \%)$, com idade média de 30,53 anos $( \pm 10)$ e 2,8 anos $( \pm 5,52)$ de trabalho com TIC. Em relação à escolaridade, $67,5 \%$ possuem ou estão realizando curso superior. Quanto à função exercida, a maior parte dos sujeitos $(57,4 \%)$ trabalha em funções administrativas. A maioria dos trabalhadores executa suas funções em empresa de grande $(47,4 \%)$ e médio porte $(32,1 \%)$ e trabalha em dois turnos, manhã e tarde $(68,1 \%)$.

\section{Instrumentos}

Para o levantamento das variáveis sociodemográficas (sexo, idade, situação conjugal, filhos, escolaridade), laborais (função, tempo de trabalho, tempo de trabalho com TIC, tamanho da organização, quantidade de horas de uso de tecnologias, tipo de tecnologia mais utilizada), psicossociais (formação para o uso de TIC, satisfação com o trabalho, realização com o trabalho, opção pelo trabalho) foi elaborado um questionário especificamente para responder aos objetivos do estudo.

A avaliação do tecnoestresse foi realizada com a Escala de Tecnoestresse (RED/TIC), desenvolvida pela equipe de investigadores da Work, Organization \& New Technologies (WONT) do Departamento de Prevención Psicosocial da Universitat Jaume I de Castellón. A RED/TIC consiste de 16 questões, subdivididas em quatro dimensões: 1) Descrença (itens 1, 2, 3, 4): avalia o quanto o trabalhador tem mantido seu interesse, significado e envolvimento com as TIC, passando a questionar se as mesmas contribuem para seu trabalho (por ex.: "Com o passar do tempo, tenho perdido o interesse sobre as tecnologias"); 2) Fadiga (itens 5, 6, 7, 8): avalia o quanto o trabalhador se sente esgotado, cansado, disperso e com dificuldade em relaxar após seu trabalho com TIC (ex.: "Tenho dificuldade em relaxar depois de um dia de trabalho com a TIC"); 3) Ansiedade (itens 9, 10, 11, 12): avalia o nível de tensão, irritabilidade, impaciência, preocupação em cometer erros, destruir ou perder informações devido ao uso inadequado (ex.: "Sinto-me tenso e ansioso ao trabalhar com tecnologias"); e, 4) Ineficácia (itens 13, 14, 15, 16): avalia o quanto o trabalhador acha difícil e se sente inseguro e ineficaz ao utilizar TIC (ex. "Em minha opinião, sou ineficaz utilizando tecnologias"). Todos os itens são avaliados em escala tipo Likert de sete pontos, variando de zero (nada/nunca) a seis (sempre/todos os dias). O escore final de cada um dos atributos é dado pela média das respostas de seus itens, sendo que médias elevadas nas dimensões são indicadores de tecnoestresse. Considerando a escala de pontuação, seriam indicadores médias iguais ou superiores a 5 (frequência de sentimentos "várias vezes por semana"). A escala validada na Espanha (Salanova et al., 2007) encontra-se disponível no site da WONT (<http://www.wont.uji.es>). A adaptação da escala (tradução para o Português do Brasil) e um estudo prévio das propriedades psicométricas (validade de conteúdo, validade de construto e confiabilidade), realizado por Carlotto e Câmara (2010a), realizada com 368 trabalhadores, identificou que o modelo teórico se ajusta satisfatoriamente aos dados. Além de ter apresentado um valor de qui-quadrado estatisticamente significativo $\left(\chi^{2}(98)=269,79, p<0,000\right)$, outros indicadores dão suporte a este resultado: a razão $\chi^{2} / \mathrm{gl}$ foi de 2,75 , com um GFI de 0,97 e o RMSR de 0,07 . O NNFI foi de 0,98 , CFI de 0,98 e PNFI $=0,79$. Todos os fatores apresentaram alfa de Cronbach superior a 0,70 (Descrença $=0,74 ;$ Fadiga $=0,89 ;$ Ansiedade $=0,77$; 
Ineficácia $=0,80$ ). Assim, os resultados mostram que o RED-TIC oferece validade fatorial e consistência interna adequada para avaliar o tecnoestresse em profissionais brasileiros.

\section{Procedimentos}

Foram realizados os procedimentos éticos conforme Resolução 196 do Conselho Nacional de Saúde (CNS), no que diz respeito à pesquisa com seres humanos. $\mathrm{O}$ estudo possui aprovação pelo Comitê de Ética em Pesquisa da instituição de afiliação das autoras. Foi esclarecido aos sujeitos e diretores das instituições de trabalho tratar-se de uma pesquisa sem quaisquer efeitos avaliativos individuais e/ou institucionais e que as respostas e os dados referentes aos resultados eram anônimos e confidenciais.

A coleta de dados foi realizada por estudantes de psicologia, bolsistas de Iniciação Científica do Laboratório de Ensino e Pesquisa em Psicologia (LAEPPSI-ULBRA/Canoas), vinculados ao projeto. Estes foram treinados em dois encontros a fim de resguardarem-se os procedimentos de padronização na aplicação. Após autorização, os instrumentos foram aplicados em salas de aulas com 255 estudantes universitários que trabalhavam com TIC e recolhidos logo após o preenchimento pelas pesquisadoras.

Em uma segunda etapa, utilizou-se a técnica em cadeias (bola de neve) (Biernacki \& Waldorf, 1981), em que os primeiros respondentes indicam outros, os quais, por sua vez, indicam outros e, assim, sucessivamente. A seleção desses indivíduos, dentro de cada cadeia, respeitou o critério de inclusão da amostra: trabalhar. Após indicação, alunos entraram em contato para convidar para participação no estudo. Os instrumentos foram entregues em horário de intervalo de trabalho dos participantes e recolhidos no dia seguinte a entrega.

O banco de dados foi digitado e posteriormente analisado no pacote estatístico Statistical Package for Social Sciences (SPSS). Inicialmente realizaram-se análises descritivas de caráter exploratório a fim de avaliar a distribuição dos itens, casos omissos e identificação de extremos. A análise dos dados foi realizada por meio da prova de correlação de Pearson (força e magnitude da associação entre variáveis contínuas), $t$ de student (comparação de médias de duas variáveis categóricas) e análise de variância (comparação de médias de 4 variáveis categóricas), considerando um nível de significância de 5\%.

\section{Resultados e discussão}

Os resultados obtidos indicam baixos índices nas quatro dimensões que compõem o tecnoestresse, considerando as possibilidades de resposta da escala ( 0 a 6 ). As médias obtidas variaram de 0,84 a 1,97 (Tabela 1). Assim, de acordo com o modelo teórico e de avaliação, não se verifica sua ocorrência na amostra investigada. Este resultado pode estar relacionado com o perfil da mesma, ou seja, os trabalhadores são jovens, com escolaridade completa ou cursando o ensino superior e trabalham há pouco tempo com TIC. Entretanto, o desvio padrão indica uma grande variabilidade de respostas.

Com relação às variáveis demográficas, verifica-se na Tabela 2 que mulheres apresentaram médias mais elevadas que homens nas quatro dimensões, resultado também identificado em estudos
Tabela 1

Média e desvio padrão das dimensões de tecnoestresse

\begin{tabular}{lcccc}
\hline Dimensões & Mínimo & Máximo & Média & $\begin{array}{c}\text { Desvio } \\
\text { Padrão }\end{array}$ \\
\hline Descrença & 0,00 & 6,00 & 1,13 & 1,16 \\
Fadiga & 0,00 & 6,00 & 1,97 & 1,44 \\
Ansiedade & 0,00 & 6,00 & 1,61 & 1,23 \\
Ineficácia & 0,00 & 5,50 & 0,84 & 0,98 \\
\hline
\end{tabular}

com trabalhadores portugueses, realizado por Pocinho e Garcia (2008), e trabalhadores espanhóis, por Salanova et al. (2007). Conforme Zauchner, Korunka, Weiss e Kafka-Lützow (2000), essa situação ocorre porque as mulheres tendem a ocupar postos de menor qualificação e participação no trabalho. Segundo Snir (2009), mesmo quando mulheres ocupam cargos de maior qualificação, tentam, diferentemente dos homens, dividir-se entre atividades profissionais e familiares. Edwards (2003) refere, ainda, existir associação da informática e da sua linguagem técnica a um domínio masculino, o que clarifica as razões do desequilíbrio em que as tecnologias de informação se difundiram entre homens e mulheres. Segundo dados do Instituto Brasileiro de Opinião Pública e Estatística [IBOPE] (2008), no Brasil, homens revelavam-se mais envolvidos com a tecnologia, com $73 \%$ deles afirmando ter acesso, contra $64 \%$ entre as mulheres.

Verifica-se que os participantes que têm filhos são mais descrentes, ansiosos e sentem-se menos eficazes frente às TIC. Mesmo sendo um grupo de trabalhadores jovens, estes participantes, provavelmente, não utilizaram e conviveram de forma tão intensa com tecnologias como seus filhos. Os filhos cresceram junto às novas TIC, possuindo o que se conhece hoje como alfabetização tecnológica (new literacy), ou seja, o conhecimento e habilidades necessárias ao uso de computadores e outros dispositivos telemáticos (International Society for Technology in Education [ISTE], 2003). Para os filhos, que, desde que nascem, já conhecem os videogames, os computadores, a internet e os telefones celulares, não existem as "novas" e as "velhas" tecnologias: existem instrumentos para informar e comunicar, jogar ou ajudar nos trabalhos escolares. Essa é uma distinção de adultos - pais, avós, educadores - para os quais, a cada surgimento de nova tecnologia, faz-se necessário adquirir novos conhecimentos e novas formas de usos sociais (Delaunay, 2008). No confronto entre seus conhecimentos e capacidade de lidar e assimilar TIC com a dos filhos, o trabalhador pode desenvolver maior ansiedade e ineficácia, podendo surgir o questionamento do quanto as TIC lhe beneficia. A autoeficácia individual e a expectativa que o indivíduo tem sobre seus resultados são influências positivas para o uso do computador (Compeau \& Higgins, 1995). Esse resultado pode ser entendido juntamente com o obtido no tocante à idade, em que quanto maior a idade maior o sentimento de ineficácia na utilização de TIC. Pocinho e Garcia (2008) encontraram todas as dimensões do tecnoestresse mais elevadas na faixa etária de 23 aos 32 anos. No Brasil, a idade aparece inversamente associada ao uso de TIC: no público entre 16 e 24 anos, 90\% têm acesso; esse percentual cai a cada degrau etário, até chegar a $23 \%$ para as pessoas com mais de 65 anos (IBOPE, 2008).

Os trabalhadores sem companheiro apresentam maior fadiga e menor ineficácia. Essa situação, comum nas situações de estresse, pode estar relacionada à falta de marcadores pessoais entre trabalho e vida privada. Geralmente, os solteiros e sem 
companheiros ficam mais horas após o expediente, levam trabalho para casa e apresentam uma maior quantidade de horas de acesso à internet. Uma pesquisa nacional por amostra de domicílios (Instituto Brasileiro de Geografia e Estatística [IBGE], 2005) revela que para os usuários jovens do Sul e do Sudeste, principalmente os de classe média e alta, a internet é lazer. Esse comportamento pode explicar o desgaste e a fadiga frente às TIC, também conhecida como fadiga informativa, resultado da sobrecarga de informação quando se utiliza a Internet (Salanova, 2007). Por ter maior envolvimento e acesso às novas TIC, atualiza-se e desenvolve um maior domínio e sentimento de eficácia frente às mesmas. A tabela 2 apresenta os índices acima discutidos.

$\mathrm{O}$ resultado do presente estudo indica que quanto menor a

Tabela 2

Relação entre dimensões de Tecnoestresse e variáveis sociodemográficas dicotômicas

\begin{tabular}{|c|c|c|c|c|c|c|c|c|c|c|c|c|c|c|c|c|c|}
\hline \multirow{2}{*}{ Variáveis } & \multirow[b]{2}{*}{$n$} & \multicolumn{4}{|c|}{ Descrença } & \multicolumn{4}{|c|}{ Fadiga } & \multicolumn{4}{|c|}{ Ansiedade } & \multicolumn{4}{|c|}{ Ineficácia } \\
\hline & & $M$ & $D P$ & $t$ & $p$ & $M$ & $D P$ & $T$ & $p$ & $M$ & $D P$ & $t$ & $p$ & $M$ & $D P$ & $t$ & $p$ \\
\hline Sexo & & & & & & & & & & & & & & & & & \\
\hline Fer & 8 & 1,28 & 1,18 & 4,22 & $<0,001$ & 2,00 & 1,49 & 0,65 & 0,05 & 1,76 & 1,34 & 3,95 & & 0,95 & 1,03 & $3,31<$ & \\
\hline Mas & 270 & 0,90 & 1,10 & & & 1,93 & 1,35 & & & 1,38 & 1,02 & & & 0,69 & 0,87 & & \\
\hline Com & & & & & & & & & & & & & & & & & \\
\hline $\begin{array}{l}\text { Sem } \\
\text { Com }\end{array}$ & $\begin{array}{c}83 \\
322\end{array}$ & $\begin{array}{l}1,19 \\
1,14\end{array}$ & $\begin{array}{l}1,20 \\
1,23\end{array}$ &,- 052 & 0,76 & $\begin{array}{l}2,23 \\
1,96\end{array}$ & $\begin{array}{l}1,42 \\
1,39\end{array}$ & 1,52 & 0,05 & $\begin{array}{l}1,67 \\
1,62\end{array}$ & $\begin{array}{l}1,67 \\
1,62\end{array}$ & $-0,22$ & 0,75 & $\begin{array}{l}0,07 \\
0,96\end{array}$ & $\begin{array}{l}1,02- \\
1,01\end{array}$ & $-3,02$ & 0,11 \\
\hline Filh & & & & & & & & & & & & & & & & & \\
\hline & 255 & 1,25 & 1,34 & 2,13 & 0,03 & 1,89 & 1,36 & $-1,24$ & 0,21 & 1,72 & 1,22 & 1,90 & 0,05 & 0,98 & 0,99 & 2,98 & $<0,001$ \\
\hline Não & 406 & 1,05 & 1,04 & & & 2,03 & 1,49 & & & 1,53 & 1,24 & & & 0,75 & 0,96 & & \\
\hline
\end{tabular}

escolaridade, ou seja, ter ensino médio, maior é a ansiedade frente às TIC (Tabela 3). De acordo com Schlegel (2009), no Brasil, há sinais de grande associação entre posição social e acesso à internet. No terceiro trimestre de 2008, o contraste entre as faixas de escolaridade era acentuado, tendo em vista que, no grupo com até o segundo grau completo, $45 \%$ usam a internet. Esse índice sobe para $79 \%$ entre os que têm superior incompleto e atinge $92 \%$ para a faixa com superior completo ou pós-graduação (IBOPE, 2008). A ansiedade pode estar relacionada à constante pressão e exigência do mercado sobre o domínio de informática e suas ferramentas para conseguir ou manter o emprego ao trabalhador com menor escolaridade.

As variáveis laborais associaram-se à realização de horas de uso de TIC fora do horário de trabalho. Quanto maior a utilização,

Tabela 3

Relação entre dimensões de Tecnoestresse e niveis de escolaridade

\begin{tabular}{|c|c|c|c|c|c|c|c|c|c|c|c|c|c|c|c|}
\hline \multirow{2}{*}{ Escolaridade } & \multirow[b]{2}{*}{$n$} & \multicolumn{3}{|c|}{ Descrença } & \multicolumn{4}{|c|}{ Fadiga } & \multicolumn{4}{|c|}{ Ansiedade } & \multicolumn{3}{|c|}{ Ineficácia } \\
\hline & & $M$ & $D P$ & $F$ & $M$ & $D P$ & $F$ & $p$ & $M$ & $D P$ & $F$ & $p$ & $M$ & $D P$ & $F$ \\
\hline Ensi & 173 & 1,27 & 1,26 & $1,880,13$ & 2,06 & 1,47 & 0,280 & 0,83 & 1,88 & 1,41 & 5,03 & 0,00 & 0,97 & 1,06 & $2,02 \quad 0,10$ \\
\hline Sup & 268 & 1,07 & 1,14 & & 1,96 & 1,42 & & & 1,59 & 1,36 & & & 0,78 & 0,92 & \\
\hline & 151 & 0,99 & 1,03 & & 1,97 & 1,36 & & & 1,36 & 1,17 & & & 0,74 & 0,92 & \\
\hline Pós-graduação & 28 & 0,97 & 1,30 & & 2,14 & 1,21 & & & 1,57 & 1,07 & & & 0,95 & 0,94 & \\
\hline
\end{tabular}

maior a descrença, a ansiedade e a ineficácia (Tabela 4). No Brasil, o acesso mais comum é na residência (45\%), seguido pelo local de trabalho (30,8\%), segundo dados do IBOPE (2008). Os usuários intensivos das TIC apresentam maior tecnoestresse do que os usuários normais ou esporádicos (Pocinho \& Garcia, 2008). Essa questão é preocupante, principalmente ao se considerar que, no Brasil, 32,1 milhões de brasileiros, 21,9\% da população acima dos 10 anos de idade, utilizaram a rede mundial de computadores em 2005. O número expressivo coloca o Brasil como o primeiro país da América Latina e o quinto no mundo quanto ao uso da internet. Ao somar as horas que utiliza a TIC na organização e fora dela, o trabalhador começa a questionar seu trabalho, se realmente ela contribui para a execução de suas tarefas, podendo, em função da sobrecarga, desenvolver ansiedade e preocupação com a quantidade de informações que tem de lidar, desenvolvendo sentimentos de insegurança e incompetência frente ao uso das tecnologias. Estudo realizado por Carlotto e Câmara (2010b) identificou relação positiva entre as dimensões de tecnoestresse e pensamento de mudar de profissão.

Tabela 4

\begin{tabular}{|c|c|c|c|c|}
\hline Variáveis & $\mathrm{DE}$ & FA & AN & IN \\
\hline Idade & $-0,002$ & $-0,069$ & 0,007 & $0,094 *$ \\
\hline Tempo de trabalho & $-0,039$ & $-0,053$ & $-0,047$ & $-0,019$ \\
\hline Tempo de trabalho com TIC & $-0,053$ & $-0,018$ & $-0,035$ & $-0,026$ \\
\hline Horas de trabalho extra organização & $0,122 * *$ & 0,056 & $0,138 * *$ & $0,146^{* *}$ \\
\hline Tamanho da organização & 0,051 & $-0,017$ & $-0,046$ & $-0,058$ \\
\hline Horas de utilização email & $0,087^{*}$ & $0,158 * *$ & 0,007 & $-0,033$ \\
\hline Horas de utilização Internet & $-0,003$ & $0,110^{* *}$ & $-0,020$ & $-0,026$ \\
\hline Horas de utilização Intranet & $-0,048$ & $0,120 *$ & $0,136^{*}$ & 0,025 \\
\hline Horas de utilização vídeoconferência & 0,214 & 0,160 & $0,414^{* *}$ & 0,181 \\
\hline Horas de utilização chat & $-0,001$ & 0,046 & $-0,018$ & 0,013 \\
\hline Satisfação no trabalho com TIC & $-0,310 * *$ & $-0,181 * *$ & $-0,236 * *$ & $-0,327 * *$ \\
\hline Realização no trabalho com TIC & $-0,352 * *$ & $-0,178 * *$ & $-0,236 * *$ & $-0,299 * *$ \\
\hline
\end{tabular}


No que diz respeito ao tipo de tecnologia, verifica-se que os que referem utilizar o celular como principal ferramenta de trabalho apresentam maior ansiedade e ineficácia (Tabela 5). O perfil do usuário de celular, no Brasil, está mais relacionado com a ocupação profissional, sendo a faixa etária de 25 e 29 anos a que mais utiliza o serviço (IBGE, 2005). O celular, além de localizar o trabalhador para eventuais necessidades e urgências, é uma ferramenta a mais de trabalho, pois, nas suas versões mais atuais, funciona como um computador disponibilizando acesso à internet, e-mails e outros serviços. Assim, todas as questões do negócio e do trabalho podem ser realizadas em tempo real. Neste sentido, pode-se pensar na ansiedade que essa situação provoca, pois o trabalhador deve estar constantemente disponível e apto a resolver as mais diversas situações à distância. Conforme Demerouti, Bakker, Nachreiner e Schaufeli (2001), a ansiedade é modulada pela presença de recursos pessoais, tais como as próprias competências mentais, a autoeficácia relacionada com a tecnologia, dentre outros aspectos. Os recursos pessoais são as características das pessoas que funcionam como mediadoras do impacto negativo das altas demandas e da falta de recursos. Dentre os principais recursos, existem características mais estáveis ao longo do tempo e também crenças sobre as próprias competências para fazer frente às novas tecnologias. A utilização de videoconferência (Tabela 4) como ferramenta de trabalho aumenta a ansiedade, podendo essa questão estar relacionada ao tipo de interação desenvolvida, às temáticas abordadas e aos horários predeterminados.

A elevação da quantidade de horas utilizadas em e-mail aumenta a descrença e a fadiga, sendo esta última também relacionada à internet e intranet (Tabela 4). Demerouti et al. (2001) assinalam que os aspectos sociais e organizacionais do trabalho com TIC requerem esforços e estão associados a

Tabela 5

Relação entre dimensões de Tecnoestresse e variáveis dicotômicas referentes ao uso de tecnologias

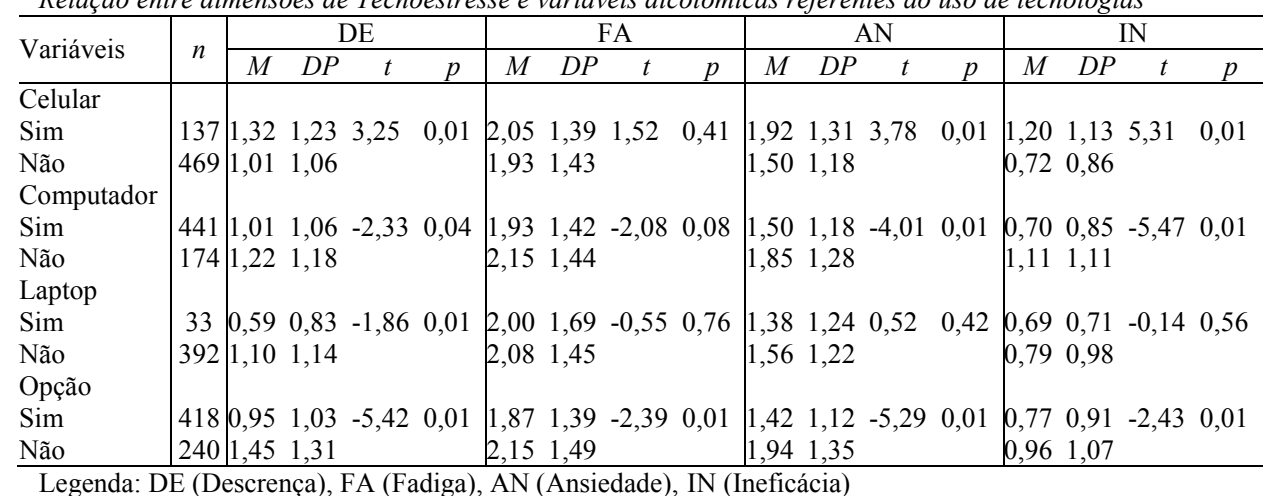

custos fisiológicos e/ou psicológicos. As principais demandas são a sobrecarga de trabalho quantitativa (muitas coisas para serem realizadas em pouco tempo disponível) e a qualitativa (dificuldade em analisar e trabalhar com muitas informações), situações características do trabalho realizado através de e-mails, internet e intranet. Todas essas ferramentas pressionam para uma resposta em tempo real, imediata, seja ela relacionada ao cliente externo como interno, no caso da intranet.

A opção por trabalhar com TIC (Tabela 5), a satisfação (Tabela 4) e a realização (Tabela 4) obtidas diminuem todas as dimensões do tecnoestresse. Esses resultados corroboram aqueles obtidos em estudo realizado por Pocinho e Garcia (2008), que identificaram associação ente altos níveis de tecnostresse e baixos níveis de satisfação laboral. Zalewska (1999) associa a satisfação no trabalho à saúde do trabalhador, pois, indivíduos mais satisfeitos apresentam melhor qualidade de saúde e menor ocorrência de doenças, tanto no que se refere à saúde física como mental.

\section{Considerações finais}

Identificar o perfil de risco para o desenvolvimento do tecnoestresse é de fundamental importância para intervenções preventivas. $\mathrm{O}$ estudo aponta para um quadro complexo de variáveis que podem prevenir ou ocasionar tecnoestresse na amostra investigada. Para a dimensão de Descrença, identifica- se um perfil constituído por mulheres, trabalhadores com filhos, com escolaridade de ensino médio, com mais horas de uso de TIC fora período de trabalho, utilização de e-mail, insatisfeitos e não realizados com o trabalho. Para a dimensão de Fadiga, delineou-se um perfil de trabalhadores do sexo feminino, sem companheiro, com mais horas de utilização de e-mail, internet, intranet, que não optaram por trabalhar com TIC, insatisfeitos e não realizados com o trabalho. Mulheres, com filhos, com ensino médio, que utilizam celular e que não optaram por trabalhar com TIC caracterizaram o perfil de risco da dimensão de Ansiedade. No tocante à Ineficácia, verifica-se como grupo de risco, mulheres, trabalhadores com idade mais elevada, com companheiro, filhos, que utilizam, na maior parte do tempo de trabalho, o celular, utilizam maior número de horas as TIC fora do horário de trabalho e que possuem sentimentos de insatisfação e não realização com o trabalho.

Os efeitos do uso das TIC dependem de fatores como as exigências e a falta de recursos gerados no trabalho, das crenças nas próprias capacidades e competências para enfrentar com êxito as mudanças tecnológicas (Pocinho \& Garcia, 2008). Todavia, ressalta-se que se deve ter cautela com relação aos resultados obtidos, uma vez que estes são decorrentes de organizações de trabalho localizadas em uma região específica do sul do Brasil, não sendo, portanto, passíveis de generalizações. É importante considerar, ainda, o efeito do trabalhador sadio, questão peculiar em estudos transversais em epidemiologia ocupacional que, 
muitas vezes, exclui o possível doente (McMichael, 1976). Essa é uma situação que pode subestimar o tamanho dos riscos identificados, porque os mais afetados não conseguem manterse no emprego, afastando-se, geralmente, por licenças para tratamento de saúde.

Certamente, há necessidade de aprofundamento dos resultados obtidos, uma vez que a literatura ainda é bastante restrita sobre esse recente fenômeno psicossocial. Assim, sugerese a realização de novos estudos, com outros delineamentos e variáveis. Porém, os resultados encontrados sinalizam a importância de intervenções que atuem sobre as variáveis laborais e psicossociais que influenciam o desenvolvimento do tecnoestresse em trabalhadores que utilizam a TIC como ferramenta essencial no seu trabalho.

\section{Referências}

Aida, R. I. R. Z., Azlina, A. B., \& Balqis, N. S. (2007). Technology, stress, academic, non academic, staff. In M. J. Dainoff (Org.), Ergonomics and health aspects of work with computers (pp.118-124). Heidelberg: Springer Berlin. doi: 10.1007/978-3-540-73333-1_15

Bejarano, V. C., Pilatti, L. A, Scandelari, L., \& Oliveira, A. C. (2006). Equipes virtuais - um estudo de caso na indústria têxtil norte-americana. Produção, 16(1), 161-170.

Biernarcki, P. \& Waldorf, D. (1981). Snowball sampling-problems and techniques of chain referral sampling. Sociological Methods and Research, 10, 141-163.

Carlotto, M. S., \& Câmara, S. G. (2010a). Tradução, adaptação e exploração de propriedades psicométricas da Escala de Tecnoestresse. Psicologia em Estudo, 15(1), 157-164.

Carlotto, M. S., \& Câmara, S. G. (2010b). O tecnoestresse em trabalhadores que atuam com tecnologia de informação e comunicação. Psicologia: Ciência e Profissão, 30(2), 308-317.

Compeau, D. R., \& Higgins, C. A. (1995). Computer self-efficacy: development of a measure and initial test. MIS Quarterly, 19(2), 189-211.

Delaunay, G. J. (2008). Novas tecnologias, novas competências. Educação em Revista, 31, 277-293.

Demerouti, E., Bakker, A. B., Nachreiner, F., \& Schaufeli, W. B. (2001). The job demands-resources model of burnout. Journal of Applied Psychology, $86,499-512$

Edwards, P. N. (2003). Industrial gender: soft/hard. In N. E. Lerman, R. Oldenziel, \& A. P. Mohun (Orgs.), Gender \& Technology: a reader (pp. 177-206). Baltimore and London: The John Hopkins University Press.

Ferreira, A. P. C. (2006). Tecnologia de informação, controle e mundo do trabalho: pensar tecnologia na ótica do trabalhador. Revista Eletrônica de Ciências Sociais, 11, 14-24.

Grimes, D. A., \& Shulz, K. F. (2002). An overview of clinical research: the lay of the land. The Lancet, 359, 57-61.

Harper, S. (2000). Managing technostress in UK libraries: a realistic guide. Recuperado de http://www.ariadne.ac.uk/issue25/technostress/intro.html

Instituto Brasileiro de Geografia e Estatística [IBGE] (2005). Pesquisa nacional por amostra de domicílios - acesso à internet e posse de telefone móvel celular para uso pessoal. Recuperado de http://www.ibge.gov.br/home/ presidencia/noticias/noticia_visualiza.php?id_noticia $=1517$

Instituto Brasileiro de Opinião Pública e Estatística [IBOPE] (2008). Indicadores mensais e trimestrais: perfil do internauta e atividades realizadas, terceiro trimestre de 2008. Recuperado de http://www.cetic.br/usuarios/ibope/ index.htm

International Society for Technology in Education [ISTE] (2003). Resources for assessment. Eugene: ISTE.

Korunka, C. (2002). Human-computer interaction and quality of working life: organizational aspects of implementing new Technologies. In E. Chifre, M., \& I. Martínez-Pérez (Orgs.), New information technology and work psychology: european trends towards fitting individual, job and organizational characteristics to new information technology (pp. 34-48). Castelló de la Plana: Publicaciones de la Universitat Jaume I.

McMichael, A. J. (1976). Standardized mortality ratios and the 'healthy worker effect': scratching beneath the surface. Journal of Occupational Medicine, 18, 165-168.

Michael, A. (1998). Stress: sinais e causas. São Paulo: Roche.

Pacheco, W., Ferreira Jr., C., Pereira, V. L. V., \& Pereira Filho, H. V. (2005). A era da tecnologia da informação e da comunicação e a saúde do trabalhador. Revista Brasileira de Medicina do Trabalho, 3(2), 114-122.

Pocinho, M. D., \& Garcia, J. C. (2008). Impacto psicosocial de la tecnología de información y comunicación (TIC): tecnoestrés, daños físicos y satisfacción laboral. Acta Colombiana de Psicología, 11(2),127-139.

Salanova, M. (2003). Trabajando con tecnologías y afrontando el tecnoestrés: el rol de las creencias de eficacia. Revista de Psicología del Trabajo y de las Organizaciones, 19, 225-247.

Salanova, M. (2005). Metodología WONT para la evaluación y prevención de riesgos psicosociales. Gestión Práctica de Riesgos Laborales, 14, 22-32.

Salanova, M. (2007). Nuevas tecnologías y nuevos riesgos psicosociales en el trabajo. Revista Digital de Prevención, 1(3), 25-34.

Salanova, M., Cifre, E., \& Martín, P. (1999). El proceso de 'tecnoestrés' y estrategias para su prevención. Trabajo y Salud, 1, 18-28.

Salanova, M., Llorens, S., Cifre, E., \& Nogareda, C. (2007). El tecnoestrés: concepto, medida e intervención psicosocial. Recuperado de http://www. insht.es/InshtWeb/Contenidos/Documentacion/FichasTecnicas/NTP/ Ficheros/701a750/ntp_730.pdf

Schlegel, R. (2009). Internauta brasileiro: perfil diferenciado, opiniões indiferenciadas. Revista de Sociologia Política, 17(34), 137-157.

Snir, R. (2009). Centrality of and investment in work and family among Israeli high-tech workers. Cross-Cultural Research, 43(4), 366-385.

Souto, S. M. O. (2006). O profissional da informação frente às tecnologias do novo milênio e às exigências do mundo do trabalho. Recuperado de http:// www.cinform.ufba.br/iv_anais/artigos/texto16.htm

Valle, B. M. (1996). Tecnologia da informação no contexto organizacional. Ciências da Informação, 25(1), 5-12.

Zalewska, A. M. (1999). Achievement and social relations values as conditions of the importance of work aspects and job satisfaction. International Journal of Occupational Safety and Ergonomics, 5(3), 395-416.

Zauchner, S., Korunka, C., Weiss, A., \& Kafka-Lützow, A. (2000). Genderrelated effects of information technology implementation. Gender, Work \& Organization, 7(2), 119-132.

Mary Sandra Carlotto, doutora em Psicologia Social pela Universidade de Santiago de Compostela, é professora do Programa de Pós-graduação em Psicologia na Pontifícia Universidade Católica do Rio Grande do Sul. Endereço para correspondência: Av. Mauá, 645, apto 504, Centro, São Leopoldo-RS. CEP.: 93110 320. Tel.: (51)93169788. E-mail: mscarlotto@gmail.com 